\title{
De Convento de San Francisco a Portales de Toluca. Análisis sociohistórico del lugar
}

\author{
From Convent of San Francisco to Toluca Portals. Socio-historical analysis \\ of the place
}

Recibido: junio 2019

Aceptado: febrero 2021

\section{Resumen}

La creación de edificios depende de dos rubros importantes: la construcción y la edificación. Lo invisible soporta lo visible, sin las historias y narrativas de la sociedad no sería posible la generación de referentes urbanos. Con esta inferencia se generó un análisis sociohistórico del Convento de San Francisco y su transformación en los Portales de Toluca, observando los comportamientos sociales e históricos que confluyeron en un lugar durante los siglos XVI al XX, entendiendo al lugar como ese espacio con una alta densidad espacio-tiempo, el espacio en donde se gesta la intensidad del ser.

\section{Palabras Claves:}

Convento de San Francisco; Portales de Toluca; lugaridad

\author{
Daniel Abner Hernández García ${ }^{1}$
}

\begin{abstract}
The creation of a building depends on two important items: construction and building. The invisible supports the visible, without the stories and narratives of society it would not be possible to generate urban referents. With this inference was generated a socio analysis of the convent of San Francisco and its transformation in the portals of Toluca, observing the social and historical behaviors that converged in a place during the sixteenth to twentieth centuries, understanding the place as this space with a highdensity space-time, the space where the intensity of the being is gestated.
\end{abstract}

\section{Keywords:}

San Francisco Convent; Toluca portals; belonging

\footnotetext{
${ }^{1}$ Nacionalidad: mexicano; adscripción: Universidad Autónoma del Estado de México; doctor en Diseño por la UAEMex correo: danielabner@ gmail.com
} 


\section{INTRODUCCIÓN}

La creación y recreación del entorno urbano depende en gran medida del conocimiento que se tenga del mismo, su pasado y su presente. Uno de los elementos que más atañe al conocimiento del entorno urbano estriba en la historia de la ciudad. La historia de la urbe se observa como un cúmulo de acontecimientos en un espacio, es decir, existe una densidad de espacio-tiempo que lo caracteriza, convirtiéndolo en lugar. Mediante la historia es posible delinear un perfil de la ciudad que fue y posiblemente un bosquejo del futuro hacia el que se dirige.

Se sostiene que todo edificio posee dos tipos de elementos que cuentan la historia tanto material como intangible del objeto en cuestión: la primera es la construcción, es decir, el aspecto físico, la fábrica del inmueble, materiales, medidas, colores, entre otras. La segunda es la edificación, en la cual se observan los elementos socioculturales que permitieron la construcción: personajes, eventos sociales, tradiciones dentro del inmueble, entre otras.

Basados en esta premisa, se realiza un análisis histórico del lugar que ocupan en la actualidad los portales de la ciudad de Toluca, Estado de México, observando la gran densidad espacio-tiempo depositada en el sitio, que durante los siglos XVI al XIX contuvo al Convento Franciscano y desde el siglo XIX a la fecha alberga a los Portales.

\section{MICROHISTORIA: LUGAR Y NARRATIVAS}

La ciudad se manifiesta de acuerdo con un tiempo y con una sociedad determinadas. Es precisamente la sociedad, el ser humano en lo individual y en conjunto, quien designa los giros históricos que plantea una urbe, misma que es producto de las relaciones que suceden entre sus propios habitantes. Como afirma Latour (Latour and Emile, 2010) la ciudad está hecha de las historias y las relaciones entre los habitantes y los objetos. Lo invisible sustenta a lo visible.

Al tratar sobre dichas relaciones, se hace indispensable el conocimiento sobre los relatos que cohesionan dichas asociaciones. Algunos autores los denominan narrativas, las cuales pueden llegar a convertirse en mitos que se erigen en el espacio-tiempo como referentes indiscutibles del rostro de una ciudad. Es importante hacer hincapié que no se pretende únicamente hacer referencia de las características físicas de algún elemento construido, sino a la relación entre dicho elemento y el ciudadano, vinculados mediante una narrativa.

Dado el carácter histórico que se plantea en el documento, resulta conveniente mencionar que se observan dos tipologías de la historia: la historia patria, la "oficial", la académica; y la historia, que Luis González y González denominó "historia matria" también conocida como Microhistoria. Ésta contempla lo cotidiano, la historia lenta y muy cercana, la historia que conlleva a lo local: inclusive a la misma anécdota.

Esta última tipología se genera en ámbitos mucho más cercanos, más locales y familiares: la microhistoria incluye las costumbres y tradiciones de un lugar, sus fiestas, sus ritos y rituales, elementos que generan identificación del ciudadano con su urbe, pues con ellos se forja la idea de "lugar" y no solo la imagen de un espacio vacío. Heidegger, usando el concepto "bauen", afirma que los espacios reciben su esencia de los lugares y no del mismo espacio (Seguel Briones, 2001). Esta idea fue bastante controversial en su tiempo, dado que se vincula con el nazismo.

Haciendo a un lado las exacerbaciones nacionalistas, resulta relevante mencionar que la idea de pertenencia, pero sobre todo de idealizar el lugar de origen, es algo bastante común en el ser humano. Salvador Azuela menciona: "El mexicano que no siente nostalgia por su provincia, representa un caso muy raro" (Azuela, 1965: XII). Así, la Microhistoria se presenta como un medio de recuperación de la memoria personal que posibilita su transformación en memoria colectiva, memoria urbana. Esa nostalgia por el terruño no es otra cosa que la lugaridad o pertenencia que el individuo posee de su ciudad y que se basa en la memoria personal.

Las tradiciones orales, leyendas, narrativas $\mathrm{y}$ relatos, fomentan el conocimiento y reconocimiento del ciudadano con su hábitat. Permite la continuidad en el tiempo, y ubica al individuo en el lugar, como lo menciona Muntañola (Muntañola Thornberg, 2009), provocando la existencia de multiplicidad de relatos, de historias, todas válidas, todas necesarias para explicar la ciudad. "...las ciudades antiguas se desplantaron sobre historias... incluso los ritos de fundación están también inmersos dentro del universo de la narrativa para ser recibidos por los futuros ciudadanos y se apropiaran de ellos" (Rubio Gutiérrez, 2014: 46). 
Ángel Garibay menciona que "Hacer patria tiene un requisito indispensable. Conocer lo que es para saber lo que puede ser" (Garibay Kintana, 1965: XI). El interés que la ciudad despierte en los habitantes será proporcional al nivel de pertenencia que los ciudadanos posean de su urbe.

\section{CONVENTO DE SAN FRANCISCO}

Son pocos los edificios que perduran en la memoria de la ciudad a pesar de que hayan desaparecido. Tal es el caso del Convento de San Francisco de Toluca, posiblemente uno de los edificios de mayor importancia en el desarrollo urbano de la ciudad a través de su historia. Al momento de desparecer engendró a otro ícono en la actual memoria colectiva: los Portales.

La historia de Toluca está profundamente ligada a la orden religiosa de los franciscanos. En el siglo XVI, después de la conquista de los poblados indígenas, los españoles pudieron lograr adquirir gran cantidad de bienes que en su país no hubieran tenido. Muchos de ellos de hicieron señores de haciendas, vivían con suntuosidad y para ello demandaban trabajo excesivo y constante de los mismos indígenas, lo que condujo a una crisis socioeconómica. Miguel Salinas menciona que en 1524 llega a la Nueva España el Apostolado de Anáhuac, una falange de frailes franciscanos, doce en total, dispuestos a evangelizar a los nativos.

La presencia de tales personajes produjo curiosidad en las mentes indígenas, pues a pesar de ser españoles, se comportaban de forma completamente diferente a los soldados conquistadores. Llegaron inclusive a tener lástima de los propios religiosos, repitiendo constantemente "motolinia" que significa "loco, enfermo, pobre" pero no en el sentido de pobreza, sino con condescendencia (De la Torre Villar, 1998: 567). Al saber esto, Fray Toribio de Benavente decide adquirir el nombre de "Motolinia".

La catequización en Toluca inicia por lo tanto en 1525, y con ello, las primeras construcciones religiosas. Miguel Salinas hace referencia a un documento del Archivo General y Público de la Nación, el tomo 2742 del ramo de tierras, en donde se menciona al cacique matlatzinca convertido al catolicismo y bautizado con el nombre de Fernando Cortés (Salinas Alanis, 1965: 32).

Debido al extravío o inexistencia de documentos, la fecha exacta de la construcción del Convento de San Francisco no es clara, sin embargo se puede inferir mediante las actividades realizadas por los franciscanos en Toluca, por lo que “...desde la cuarta década del siglo XVI, hubo en Toluca franciscanos que vivían en comunidad y que habitaban un convento" (Salinas Alanis, 1965: 35).

En un intento por recuperar aspectos históricos del Convento de San Francisco, en 1688, Fray Alonso de Hita decide hacer uso de información testimonial, recurriendo a los descendientes de los fundadores del Convento. Así localiza a Pascual de Angulo, bisnieto de Juan Cortés Coyotzin, rey de los matlatzincas:

"Afirmó también que sabía por tradición que cuando se trastó de construir el convento de San Francisco, algunos religiosos pretendian edificarlo en el sitio conocido como las Trojes -al pie de los cerros, entre santa Bárbara y San Luis- y otros donde está la Ermita de San Juan Evangelista -hoy San Juan Chiquito-; pero siendo ambos puntos unos sitios desacomodados, por hallarse entre cerros, se optó por un lugar situado en la planicie" (Salinas Alanis, 1965: 37).

Debido a esta decisión, el recién converso Juan Cortés Coyotzin decide donar un solar, cuyas medidas aproximadas eran 270 metros de largo, de oriente a poniente, y 180 de ancho, de norte a sur (Salinas Alanis, 1965: 40). Además de donar el solar, Juan Cortés decide demoler sus casas ubicadas en San Luis Obispo y usar ese material para la construcción del templo franciscano. Miguel Salinas menciona que posiblemente las mencionadas casas o palacios de Juan Cortés eran en realidad dependencias del teocalli, o inclusive el miso teocalli para Tolotzin (Salinas Alanis, 1965). En este gran terreno se ubican actualmente la Plaza González Arratia y los Portales. De acuerdo al mismo autor, en 1575 se celebra la primera misa en la nueva iglesia franciscana, después de años de evangelización (Salinas Alanis, 1965: 39).

A mediados del siglo XVI se construye en dicho terreno la Capilla de la Santa Cruz de los Otomites, asimismo algunas habitaciones para los franciscanos. Posterior a ello, se construyó “...la iglesia de San Francisco y sus capillas; el convento y sus amplias dependencias; luego 
la iglesia de la Tercera Orden y los edificios que le están anexos; y en el transcurso de los años, todas las demás construcciones..." (Salinas Alanis, 1965: 41). Todo el solar fue limitado perimetralmente: la parte del cementerio tenía una serie de arcos invertidos, la de la huerta del convento solo era un muro.

Basándonos en un plano del Convento de San Francisco, obtenido en el Archivo Histórico de Toluca, se observan los nombres de las calles que corresponderían en la actualidad a los siguientes: Calle Real es la actual Avenida Independencia, Calle del Maíz actual Andador Constitución, Calle de San Francisco corresponde a la Avenida Hidalgo y la Calle de Riscos es la actual calle de 5 de febrero. El mismo plano es analizado por Nicolás León (León, 1969: 61), destacando los siguientes elementos:
1 - Iglesia de la Santa Veracruz

17- Sacristía de la Iglesia

20- Patio del Convento

34- Iglesia de San Francisco (Iglesia Grande)

38- Capilla del Rosario

54- Iglesia del Tercer Orden

55-Antigua Capilla de San Pablo edificada en 1575 , en la cual se celebró la primera misa.

Actualmente, lo único que subsiste del antiguo Convento es la Iglesia de la Santa Veracruz, la Capilla Exenta y la Parroquia del Sagrario, antigua Capilla del Tercer Orden. En reciente visita a las oficinas de dicha parroquia se logró fotografiar el único arco que permanece de lo que fue la Capilla de la Santa Cruz de los Otomíes, arcos que están representados en el plano con el número 55.

Figura 1. Redibujo basado en el plano del Convento de San Francisco elaborado por Carlos Suárez (León, 1969)

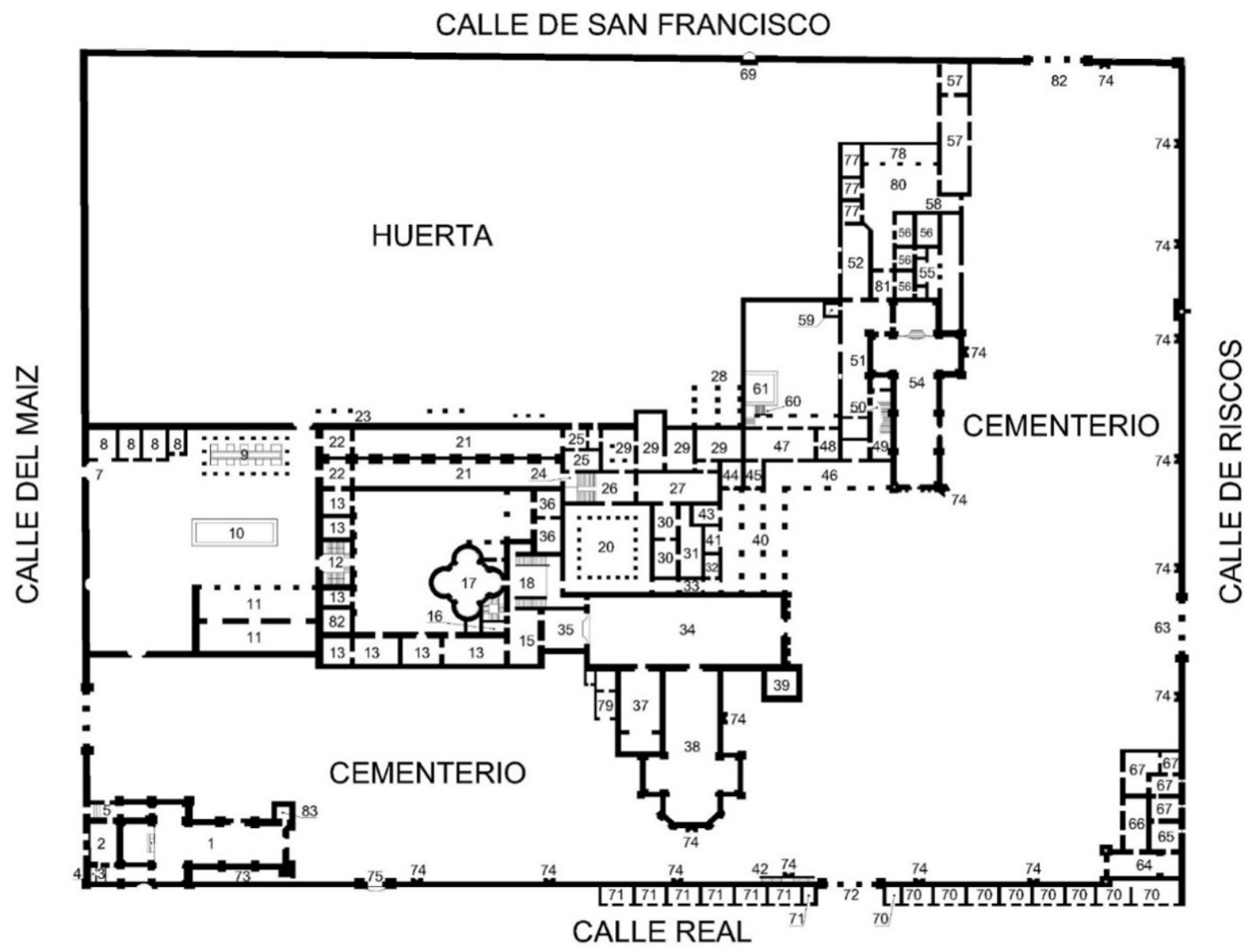

Fuente: Elaborado por el autor 
Figura 2. Arco de la Capilla de Santa Cruz de los Otomíes (abajo y derecha)
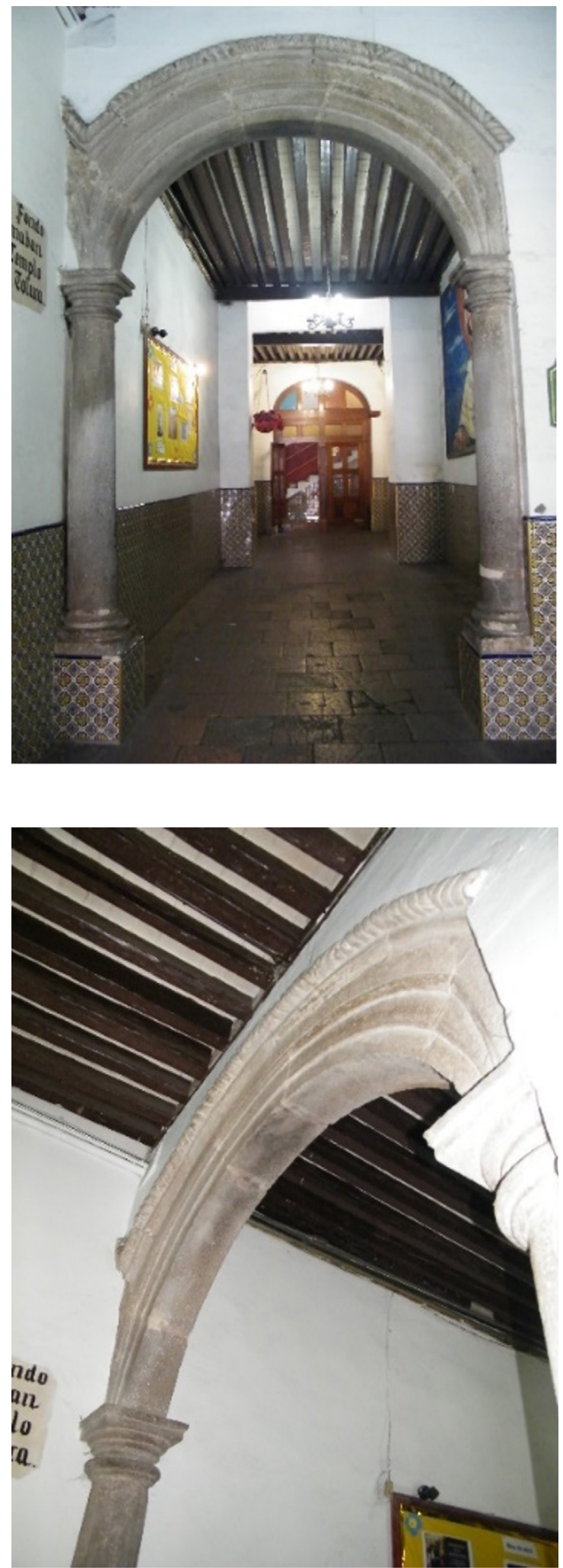

Fuente: Fotografias por el autor

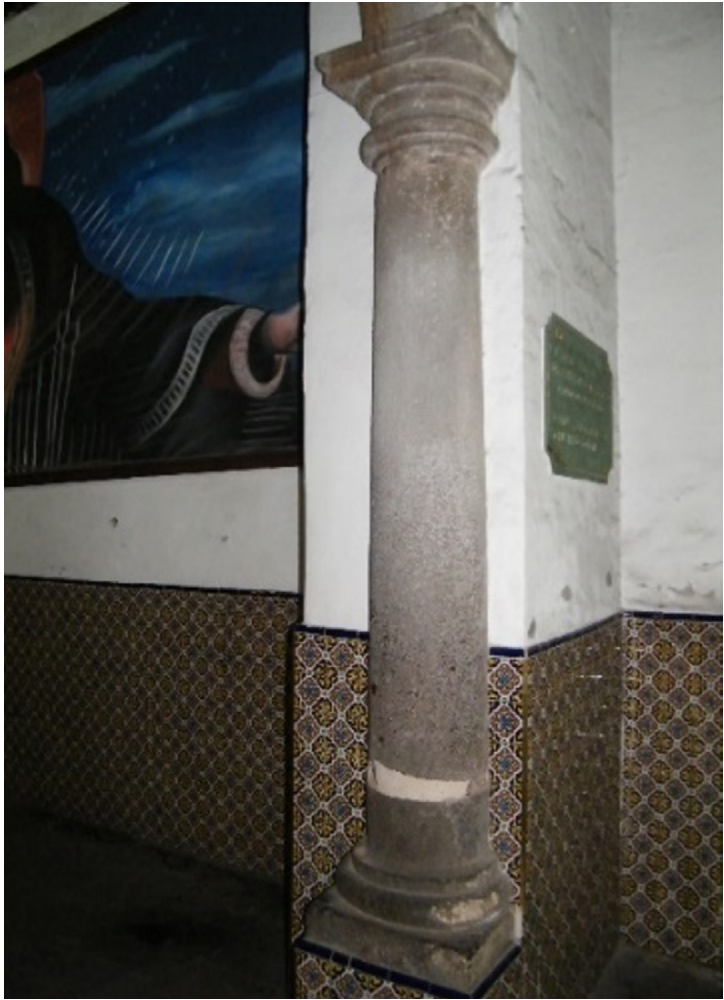

Se observa de igual manera, que la Iglesia de San Francisco (número 34 en el plano anterior) tenía el acceso ubicado hacia el Poniente, al igual que todas las iglesias de la misma orden. De los aspectos arquitectónicos se menciona:

"La fachada de la iglesia no ostentaba primores arquitectónicos; era de una pobreza verdaderamente franciscana... La puerta del templo era de medio punto... Al lado septentrional de tan pobre fachada, unida a ella se alzaba la torre, cuya elevación puede calcularse entre cuarenta y cincuenta metros. El basamento de la torre era...un tronco de pirámide cuadrangular" (Salinas Alanis, 1965: 46).

Salinas se aventura a dar medidas aproximadas de la nave de la iglesia, mencionando que pudo haber tenido 52 metros de longitud por 14 de anchura, es decir, no había crucero pues era una sola nave. El techo era de:

“...tijera formado por un armazón de vigas de cedro, cubiertas por gruesas tablas de la propia 
madera, y ésta a su vez, forrada con gruesa lámina de plomo. Por el interior, la techumbre ostentaba hermoso artesonado, hecho con listones de madera, primorosamente combinados, que ofrecían a la vista bellas figuras doradas y pintadas de diversos colores, principalmente de rojo" (Salinas Alanis, 1965: 51).

El mismo autor menciona que dicha madera pudo haber sido sustraída de los bosques antiguos de Santiago Tlaxomulco, que llegaban hasta los límites de la ciudad de Toluca.

El Convento de San Francisco llegó a ser conocido en la Nueva España como un centro educativo de alto nivel. Fray Jerónimo de Mendieta menciona que "...la casa de Toluca es única para este propósito del estudio, porque tiene todas las partes que se requieren, y a esta causa la habian de dedicar para perpetuo estudio" (Salinas Alanis, 1965: 53). La biblioteca que poseía el Convento llegó a ostentar, de acuerdo con Fray Luis Malo, cerca de 9 mil volúmenes, mismos que durante la Reforma, fueron trasladados al Convento del Carmen y de ahí fueron cedidos al Instituto Literario de Toluca (Salinas Alanis, 1965).

El Convento de San Francisco fue determinante en la conformación de la naciente ciudad de Toluca. Dentro de sus muros se sucedieron hechos determinantes en la vida de la ciudad. El 29 de febrero de 1824 (Salinas Alanis, 1965) se juró obediencia al Acta Constitutiva de la Federación Mexicana, ceremonia a la cual asistieron las autoridades eclesiales y representando al gobierno municipal, estuvo José María González Arratia en su papel de Presidente Municipal.

Sánchez Arteche (2013) apunta dos hechos que determinaron la desaparición del antiguo complejo conventual franciscano en la ciudad de Toluca. El primero está representado por las Leyes de Reforma, que irrumpieron en la provincial vida de la naciente ciudad a mediados del siglo XIX. En dichas leyes se establecía, entre otras cosas, la supresión de fueros del clero y el ejército, la obligación de vender casas y terrenos a instituciones civiles y eclesiásticas, la prohibición del cobro de derechos y obvenciones parroquiales así como el diezmo, la nacionalización de los bienes eclesiásticos y la exclaustración de monjas y frailes.

El segundo hecho ocurre en 1860, cuando un cañonazo de los generales conservadores Miguel Miramón y Leonardo Márquez (apodado el Tigre de Tacubaya) destruyó el altar de la Iglesia de San Francisco (Salinas Alanis, 1965), en un intento por sorprender a los generales liberales Felipe Berriozábal y Santos Degollado. Hay relatos que mencionan el altar no fue lo único que sufrió daños, sino el edificio completo, pues dicho cañonazo se disparo hacia la torre del campanario, misma que cayó sobre el techo de la nave principal (Sánchez Arteche, 2013: 104).

Sin embargo, se observa necesario agregar un tercer hecho, mismo que será tratado en el siguiente apartado, y que traería como consecuencia la desaparición paulatina del Convento: la construcción de los Portales.

\section{LOS PORTALES}

Si bien la etapa colonial de la ciudad de Toluca está íntimamente ligada a la orden franciscana, los primeros años de la etapa independiente se vinculan sin duda a un personaje originario de la misma ciudad de Toluca: José María González Arratia.

Dedicado al comercio, González Arratia se desempeñó como abastecedor de cárnicos, labrador, entre otros, pero el oficio que definió su presencia en Toluca fue el de constructor. Sin estudios especiales, González Arratia comenzó a construir casas habitación, tiendas, e inclusive obra pública (Salinas Alanis, 1965).

En 1830 surge el Estado de México como entidad independiente a la capital del país, trayendo como consecuencia la búsqueda del lugar indicado que pudiera recibir a los Supremos Poderes. Salinas (1965) menciona que los funcionarios de gobierno salieron de la Ciudad de México junto a sus familias, y no encontraron inmuebles propios para habitar, ya que el numero de edificios vacíos estaba muy disminuido. Ya desde 1826, el entonces secretario del Ayuntamiento Manuel de Izaguirre pretendía darle un mejor uso al espacio de la huerta del Convento de San Francisco. Fue durante el periodo municipal de Luis Madrid, y con el apoyo del gobernador Melchor Múzquiz, que se lograron resolver las dificultades que imposibilitaban el proyecto. Alfonso Sánchez Arteche señala las razones que según Luis Madrid, sustentaban la existencia del proyecto:

"Un aumento de puntos de comercio que hace aumentar las relaciones de los pueblos... 
un lugar de recreo y desahogo para los que cansados de las fatigas del día desean la concurrencia o sociedad...un crecimiento en el numero de habitaciones, cuya falta es hoy muy palpable, un impulso a las artes que tengan que emplearse en su fabricación, un nuevo recurso y seguro a las arcas municipales y acaso un estimulo que despierta el espíritu de empresa, que por desgracia duerme aletargado en este país" (Sánchez Arteche, 2013: 102)

González Arratia logró formar un grupo de inversionistas para que comprara cada uno una fracción de terreno del Convento de San Francisco. Dicha acción obligaba al comprador a que edificara por si mismo una casa en el terreno correspondiente.

El 6 de febrero de 1832 se dio inicio a la obra de los portales (Salinas Alanis, 1965: 186), comenzando con 6 casas, construyendo un total de 19 residencias. Miguel Salinas (1965) menciona detalladamente los nombres de los dueños originales de tales construcciones. El costo total de la obra fue de $\$ 164,500$ pesos (Salinas Alanis, 1965: 188). En 1833 surge una epidemia de cólera en la ciudad, reduciendo considerablemente la población de Toluca, por lo que la construcción se interrumpió. Posterior a ello se reinician las actividades, con tanto empeño que cuando en 1835 Carlos María de Bustamante visita Toluca, describe:

“En la nueva portalería...conté quince faroles hermosísimos de cristal, pendientes de los techos, con reverberos. Hay en el mismo Portal una Gran Sociedad y cafés decentes, al parecer; no entré en ninguno, pues estas casas son el centro y asilo de la gente baldía y holgazana. Alli hay algunos talleres de sastres $y$ cajones salientes en el mismo Portal, con uno bien provisto de muñecos de mala mano para los niños” (De Bustamante, 1969: 55).

De acuerdo con Miguel Salinas (1965), al concluir la construcción en noviembre de 1836 , González Arratia gestionó, en beneficio del Ayuntamiento, el cobro de un impuesto específico para cada puesto comercial que fuera a colocarse en los nuevos portales, aunque como se mencionó en párrafos anteriores, el Presidente Municipal Luis Madrid ya contemplaba la aplicación de rentas como fuente de ingresos para el municipio.

Figura 2. Redibujo del plano de subdivisión del Convento de San Francisco (León, 1969)

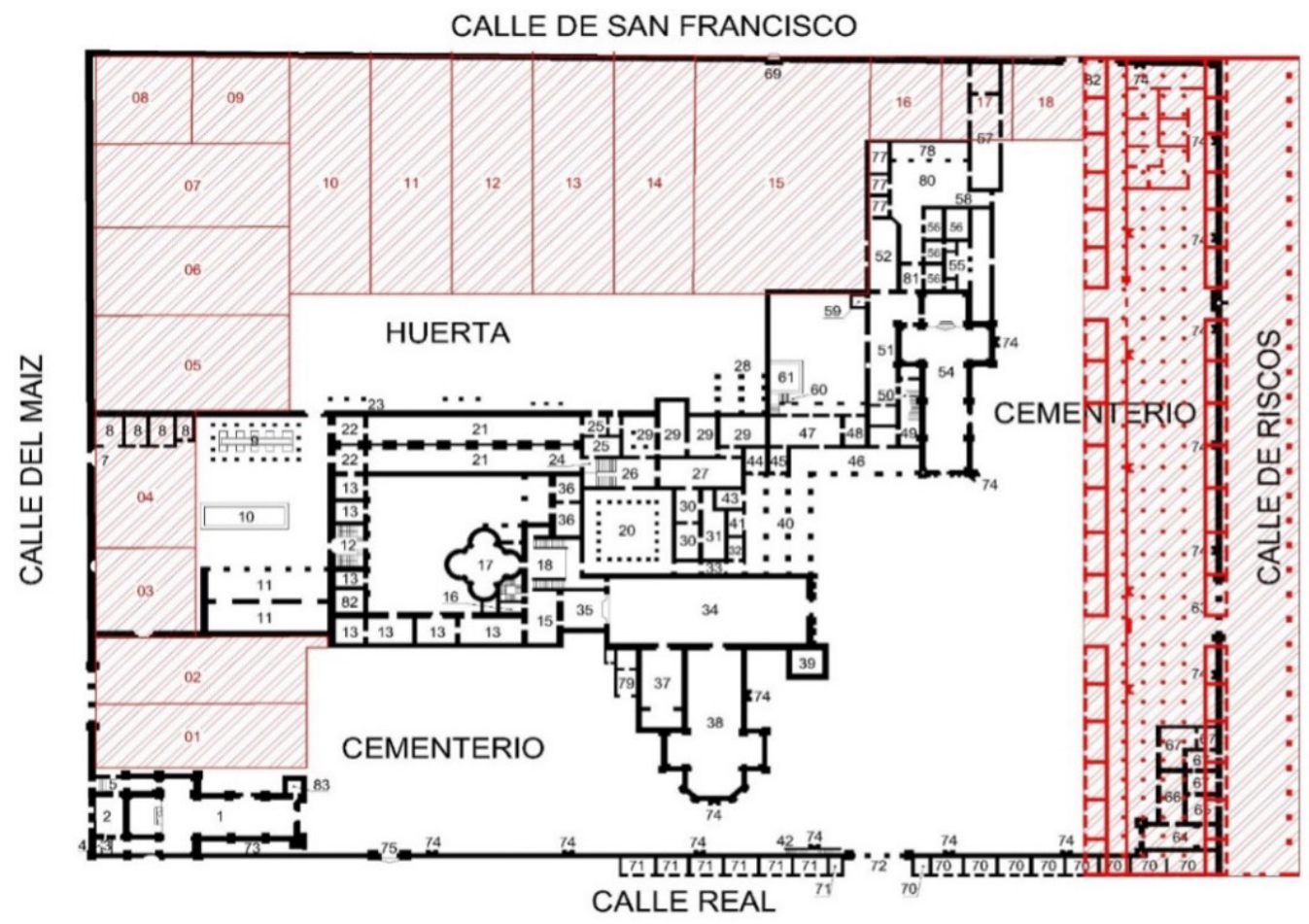

Fuente: Elaborado por el autor 
Resulta interesante que, en reiteradas ocasiones, los elementos referenciales de una ciudad no necesariamente se rigen por cánones estéticos definidos o en boga. Las mismas crónicas de la construcción de los portales de Toluca mencionan la evidente desproporción en los $\operatorname{arcos}$ y la ausencia de estilo arquitectónico, aunque lo llegan a vincular con el toscano. De acuerdo con Miguel Salinas (1965), la altura total de dicha construcción llegaba a las doce varas, es decir, 10.06 metros. Se menciona la existencia de dos niveles: el inferior conteniendo a los arcos que definen los portales, y el superior mostrando los balcones. Como se ha mencionado, cada fracción de terreno generó una casa “... de bastante capacidad y muy buena distribución en sus piezas para que pueda alojarse cómodamente una familia rica" (Salinas Alanis, 1965: 189).

La altura de cada arco es de $4 \frac{2}{3}$ varas, que en metros representan 3.981. Los pilares son de base cuadrangular con una vara de ancho o cerca de los 83 centímetros de cada lado. Los muros son de adobe y los arcos fueron hechos con piedra y ladrillo. Ésta primera etapa de construcción generó 81 arcos, de los cuales, 37 se encontraban en el actual andador Constitución, antigua calle del Maíz, y 44 en la actual avenida Hidalgo, antiguas calles Matamoros y Morelos. Carlos María de Bustamante señala “...la nueva portalería... que es mucho mas ancha y aun doble de la del Portal de Agustinos" (De Bustamante, 1969: 55), haciendo referencia a la construcción ubicada en la ciudad de México. El ancho de los portales de Toluca para el libre paso es de siete varas o 5.86 metros, cubriendo una longitud total, en su primera etapa, de 384.6 metros o cuatrocientas cincuenta y nueve varas (Salinas Alanis, 1965).

Figura 4A. Los Portales de Toluca. Óleo de Luis Coto de 1887, después de la segunda etapa de construcción a instancias de Buenaventura Merlín

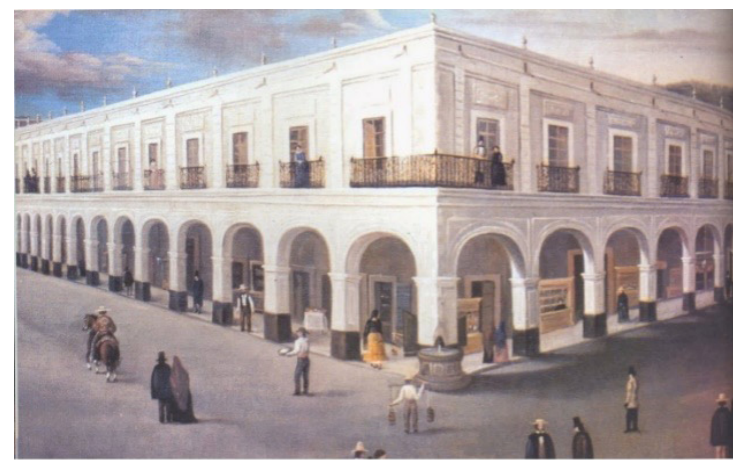

Figura 4B. Portales de mercaderes y agustinos de la Ciudad de México

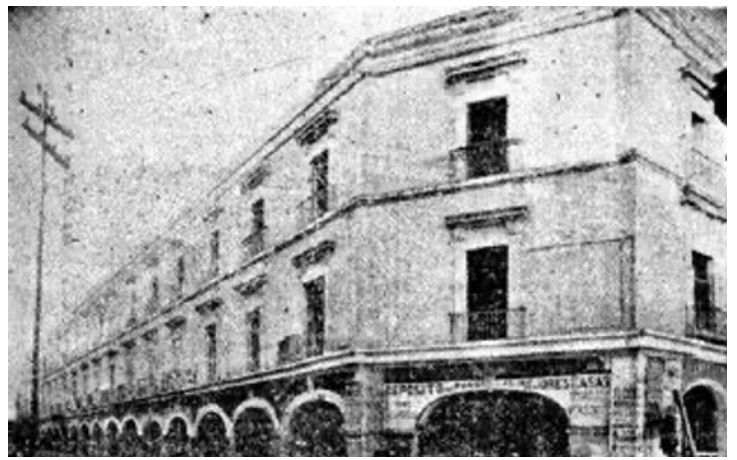

Fuentes: $4 A$ - http://smgeem.blogspot.mx/2015/02/ acontecimientos-y-destellos-de-la.html; $4 B$ - http://www. elcentrohistorico.com.mx/lugares-portal-de-mercaderes.html

En 1850 algunos vecinos de la ciudad de Toluca plantean la necesidad de una nueva iglesia Parroquial ante el guardián del Convento, ya que se pretendía que dicha construcción estuviera de acuerdo con el crecimiento y desarrollo económico que apuntaba la ciudad. Para dar su consentimiento, el fraile Mariano de la Peña solicitó se asegurara una suma de $\$ 50,000.00$ que era el estimado de la obra, sin embargo solo se reunieron $\$ 10,000.00$. Aunado a lo anterior, en las juntas de trabajo que se tenían para definir el proyecto, hubo varias discrepancias con respecto a la ubicación de la construcción: algunos, apoyados en opiniones de los arquitectos Aranda y Robles Pezuela, querían colocar la iglesia frente a la plaza principal; otros a un lado de la antigua parroquia, y algunos más pretendían que se construyera el nuevo edificio envolviendo la antigua parroquia a fin de demoler a esta última solo cuando estuviera lista la nueva (León, 1969).

Sin embargo, este primer intento no prosperó y el desánimo llegó pronto. Años más tarde, en 1866 el fraile Buenaventura Merlín rescató la idea de construir una nueva iglesia. Con el permiso del arzobispo Lázaro de la Garza y Ballesteros y las gestiones del mismo fraile Merlín, en julio de 1867 se toma la decisión de demoler la antigua iglesia de San Francisco (Salinas Alanis, 1965), la cual ya acusaba bastante deterioro. Se encomienda el proyecto de la nueva iglesia al Ing. Agustín Carrillo, colocando la primera piedra el 12 de mayo de 1867. Sin embargo, a pesar del ahínco mostrado por el fraile Merlín, no se tenia el apoyo económico suficiente, por lo que se toma la decisión 
de construir la sección poniente de los portales, cuyo usufructo beneficiaría la empresa. En un periodo de diez años, Buenaventura Merlín solo logró construir 27 arcos. Los últimos arcos fueron construidos por Agustín Millán, concluyendo la construcción en 1917 (Sánchez Arteche, 2013).

\section{CONCLUSIONES}

En el presente documento se plantea el desarrollo histórico de los dos edificios que probablemente han sido los que mayor influencia han tenido en el desarrollo de la ciudad de Toluca: el Convento Franciscano y los Portales. Dos edificios que son producto de la sociedad que los habitó, el primero por una sociedad completamente influida por el pensamiento religioso, el segundo por el laicismo, que si bien no es manifiesto abiertamente, tuvo arraigo notable en la "taza de plata con olor a sacristía".

Latour menciona que lo invisible, estas relaciones generadas entre objetos, edificios y personas es lo que sostiene lo visible, lo tangible. La historia es uno de los elementos que permite al ciudadano apropiarse de su urbe. Pero solo cuando este conocimiento histñrico se entrecruza con la cotidianidad del colectivo es cuando se da la pertenencia como tal. La pertenencia no emana solamente del patrimonio construido, la fuerza de la identidad se ubica en las relaciones, el uso, la vida que se desarrolla en los edificios y los espacios, los cuales, al tener una densidad de espacio tiempo en donde ocurre una cantidad considerable de sucesos vivenciales, se convierten en lugares.

Actualmente existe un acercamiento de los habitantes hacia la historia de su ciudad, el interés por conocer su urbe y conocerse a sí mismos. En el proceso histórico del lugar que un tiempo ocupo el Convento de San Francisco y que ahora lo hacen los portales, se logra observar que la ciudadanía es determinante en el proceso de generación de referentes. Puede existir el apoyo económico y político, pero sin el aspecto social, del ciudadano, no es posible generar apego ni identificación con un espacio. Las determinaciones políticas en cuanto a construcción y conservación urbanos no siempre generan identidad. En 2015 se realizó una investigación en la Maestría en Diseño de la UAEMex (Hernández García 2015) con respecto a los portales de Toluca y su relación con la ciudadanía. Usando instrumentos como encuestas y entrevistas, se vislumbró un concepto que por casi cinco décadas ha permeado la opinión del toluqueño: vacíos de identidad. Dichos vacíos resultan de la eliminación de referentes urbanos de la trama antigua y la consecuente construcción de edificios que no alcanzan a cubrir el imaginario colectivo. Así, sin referentes surge la confusión y con ésta el desapego a la ciudad. En 1927 Miguel Salinas concluía uno de los capítulos de su libro "Datos para la Historia de Toluca" con un párrafo que resulta totalmente actual: "Ojalá se libre Toluca de la manía insensata de destruir lo antiguo, y sepa guardar con amor sus viejos monumentos" (Salinas Alanis, 1965: 108). C

\section{REFERENCIAS BIBLIOGRÁFICAS}

Azuela, Salvador. «Crónica de Toluca.» En Toluca. Crónicas de una ciudad. Antología, de Mario Colín (Compilador), XII-XIV. Toluca, Estado de México: Gobierno del Estado de México, 1965.

De Bustamante, Carlos María. Viaje a Toluca en 1834. Versión Paloegráfica. Primera. Editado por Mario Colín. Toluca, Estado de México: Gobierno del Estado de México, 1969.

De la Torre Villar, Ernesto (selección, prefacio, notas y tablas cronológicas). Lecturas históricas mexicanas. (PDF) Segunda - México, DF: Universidad Nacional Autónoma de México, 1998.

Garibay Kintana, Angel María. «Tacita de plata.» En Toluca. Crónicas de una ciudad, de Mario Colín (Compilador), IX - XI. Toluca, Estado de México: Gobierno del Estado de México, 1965.

Hernández García, Daniel Abner. Diagnóstico de la relación histórica entre identidad e hitos de los portales de Toluca. Toluca: UAEM FAD, 2015.

Latour, Bruno, y Hermant Emile. París, ciudad invisible. Toluca, Estado de México: UAEM, 2010.

León, Nicolás. El Convento Franciscano de la Asumpción de Toluca. Editado por Mario Colín. Toluca, Estado de México: Gobierno del Estado de México, 1969.

Muntañola Thornberg, Josep. Topogénesis. Fundamentos de una nueva arquitectura. Barcelona, España: UPC, 2009.

Salinas Alanis, Miguel. Datos para la historia de Toluca. Segunda. Toluca, Estado de México: Gobierno del Estado de México, 1965. 
Sánchez Arteche, Alfonso. Las siete Tolucas y otros ensayos. Toluca: H. Ayunatmiento de Toluca, 2013.

Seguel Briones, Leonardo. «El territorio intersticial de lo cotidiano.» Urbano, $\mathrm{n}^{\circ}$ Julio (2001): 16-19. 